\title{
Changeover from unsignaled to signaled avoidance with and without a feedback stimulus in rats*
}

\author{
PIETRO BADIA \\ Department of Psychology, Bowling Green State University, Bowling Green, Ohio 43403 \\ and \\ STUART CULBERTSON \\ The American University, Washington, D.C. 20016
}

\begin{abstract}
Two experiments are reported in which, by pressing a lever, unsignaled avoidable shocks could be changed to signaled avoidable shocks for periods of $1 \mathrm{~min}$, after which unsignaled avoidance was automatically reinstated. A correlated stimulus identified the signaled schedule. Under these conditions, Ss changed over at a rate sufficient to remain in the signaled schedule more than $90 \%$ of the time. Both experiments showed that changeover performance was under the control of the correlated stimulus. Presenting the signaled schedule without the correlated stimulus did not maintain changing over. The second experiment showed that a 1-sec presentation of the correlated stimulus was sufficient to maintain changeover performance. The results were attributed to the conditioned reinforcing properties of the correlated stimulus.
\end{abstract}

Previous research has shown that Ss will change from a situation in which shocks are unsignaled to one in which they are signaled. The degree of control Ss had over shock was not a factor since Ss chose the signaled condition whether shocks were avoidable (Badia, Culbertson, \& Lewis, 1971), escapable, or inescapable (Badia \& Culbertson, 1972). In this earlier research, it was difficult to assess whether choice of the signaled condition was controlled by the stimulus (signal) identifying a shock period or the stimulus identifying a shock-free period (safety). The two experiments reported here deal with signals identifying shock periods, while the second experiment deals with the conditioned reinforcing properties of a stimulus identifying safety.

In the study by Badia et al (1971), Ss were given signaled shock for several sessions after which they were given unsignaled shock. While in the unsignaled condition, a response on a changeover lever immediately produced a correlated stimulus and changed the condition to signaled shock for fixed 1 -min periods. In the presence of the correlated stimulus, each shock was preceded by a signal. After showing that Ss changed to the condition that included both correlated stimulus and signal, the separate control exerted by these stimuli was assessed. Badia et al report two unexpected findings. First, considerable control over changeover responding occurred when only the correlated stimulus was presented while the signaled schedule was withheld. Second, little control over changeover occurred when the signaled schedule was presented while the correlated

*This research was supported, in part, by Grant GB-33725 from the National Science Foundation.

tReprints may be obtained from Pietro Badia, Department of Psychology, Bowling Green State University, Bowling Green, Ohio 43403. stimulus was withheld. It was noted by Badia et al that the control exerted by the correlated stimulus alone was similar to that of the regular changeover condition where both the correlated stimulus and the signaled condition followed a response. Thus the correlated stimulus, and not the signaled schedule, seemed to be the reinforcer maintaining changeover performance.

In their account of these two findings, Badia and Culbertson (1972) suggested that the control exerted by the correlated stimulus was based upon its establishment as a conditioned reinforcer. They argued that the correlated stimulus acquired its reinforcing properties because under the signaled schedule shock occurred only in the presence of the compound of correlated stimulus and signal and never in the presence of the correlated stimulus alone. Therefore, the correlated stimulus alone reliably identified a shock-free (safe) period, and the compound of correlated stimulus and signal identified a shock (unsafe) period. The authors also speculated about why the signal condition without the correlated stimulus failed to control changeover performance. They concluded that when the correlated stimulus was no longer part of the contingency, a changeover response no longer provided immediate reinforcement (i.e., the correlated stimulus) indicating that a shock-free period was in effect.

It was assumed by Badia et al (1971) that the reinforcing event controlling changeover performance was the immediate presentation of the correlated stimulus (safety). Given this assumption, it might be expected that changing from unsignaled to signaled avoidance may be controlled as effectively with an immediate $1-\mathrm{sec}$ presentation of the correlated stimulus as with one lasting the entire 1 -min changeover period. The second experiment dealt with this issue, while the first served another purpose. 


\section{EXPERIMENT I}

The first experiment investigated the procedure whereby the signaled schedule without the correlated stimulus was contingent upon a changeover response. In the previous experiment (Badia et al, 1971), changeover responses resulted in 1-min presentations of the signaled schedule with a response-shock interval of $20 \mathrm{sec}$. Under this condition, Ss could receive a maximum of only three signals per changeover, and the delay between a changeover response and signal (maximum $15 \mathrm{sec}$ ) may have been a factor. Perhaps Ss would continue changing to the signaled schedule without the correlated stimulus if the delay period between a response and the signaled schedule were reduced. Therefore, the response-shock interval in Experiment I was reduced to $10 \mathrm{sec}$. This reduction resulted in a maximum delay of only $5 \mathrm{sec}$ between a changeover response and signal and increased the maximum number of signals per changeover period $(1 \mathrm{~min})$ from three to six.

\section{Method}

Subjects. Three female albino rats of the Sprague-Dawley strain (Holtzman), between 130 and 160 days old, served as Ss.

Apparatus. All Ss were tested in operant chambers modified so that the grid bars were perpendicular to the levers. Two boxes, each with two Gerbrands levers, were enclosed in IAC acoustical chambers. These chambers were $36.8 \mathrm{~cm}$ long, $25.4 \mathrm{~cm}$ wide, and $12.7 \mathrm{~cm}$ high. The levers required about $20 \mathrm{~g}$ $(0.196 \mathrm{~N})$ to depress and were $5.08 \mathrm{~cm}$ from the side along the $25.4-\mathrm{cm}$ wall, $7.65 \mathrm{~cm}$ above the grid floor. The right lever was used for avoidance responding and the left for changeover responding. A $1,400-\mathrm{Hz}$ tone $(86, \mathrm{~dB})$ served as the preshock warning stimulus. Termination of a lamp (28ESB) with a $1.27-\mathrm{cm}$ jeweled lens, located above the left bar, signaled the beginning of the experimental session, while its onset signaled the end of the session. A $2.54-\mathrm{cm}$ white jeweled lens, illuminated with a $24-\mathrm{V}$ bulb $(509 \mathrm{~K})$, was mounted above the right lever and served as the correlated stimulus. The correlated stimulus was always on during signaled avoidance, and off during unsignaled avoidance. A constant wattage shock source (BRS Inc.) delivered a .32 -sec shock at $75 \mathrm{~mW}$. Grid bars were of $0.64-\mathrm{cm}$ stainless steel and were spaced $1.27 \mathrm{~cm}$ apart, center-to-center. The walls and response levers served as one contact in the grid scrambling circuit.

Procedure. Ss were run in 6-h sessions every other day. The following intervals prevailed for signaled avoidance: response-shock $=10 \mathrm{sec}$, shock-shock $=5$ or $10 \mathrm{sec}$, response-signal $=5 \mathrm{sec}$, and signal-shock $=5 \mathrm{sec}$. For unsignaled avoidance, the response-shock interval was $10 \mathrm{sec}$ and the shock-shock interval was 5 or $10 \mathrm{sec}$. Two Ss (A89 and A90) first received a shock-shock 5 -sec interval and later received a shock-shock 10-sec interval, while one S (B11) received the reverse. In the signaled condition, every response reset the response-shock (or response-signal) interval. The signal came on if $5 \mathrm{sec}$ passed without a response. If Ss allowed $10 \mathrm{sec}$ to elapse, shock was delivered and the shock-shock interval began. Signals were not presented during the shock-shock interval. While in signaled avoidance, Ss could respond in the absence of the signal and avoid both the signal and shock, or respond in the presence of the signal to terminate it and avoid shock.

Initial Training: Signaled Avoidance. At the beginning of the experiment, each $\mathrm{S}$ received signaled avoidance training identified by the correlated stimulus. Responses on the changeover lever, and the consequent amount of time that would have been spent in the changeover condition had these responses been effective, were recorded, though these responses produced no stimulus change. This latter measure served as the operant level baseline.

Changeover for Signaled Avoidance (CO). After signaled avoidance responding stabilized (stabilization never requiring fewer than three 6-h sessions), Ss began the next session with unsignaled avoidance. With unsignaled avoidance, Ss continued to avoid on the right lever; however, depression of the left (changeover) lever resulted in immediate onset of the correlated stimulus and put into effect the signaled avoidance schedule. A changeover response produced the correlated stimulus and the signaled avoidance schedule for a $1-\mathrm{min}$ period; additional responses on this lever within the $1-\mathrm{min}$ period were ineffective. At the end of this period, the correlated stimulus terminated and Ss could remain in the unsignaled condition or reinstate the signaled one by making another changeover response.

Changeover Extinction (Correlated Stimulus But No Signal-EX 2). The effects of presenting the correlated stimulus alone were revealed by the EX 2 extinction procedure. Ss were placed in the unsignaled condition, and a response on the changeover lever produced only the correlated stimulus for a $1-\mathrm{min}$ period, and not the signal. In this condition, Ss received only unsignaled avoidance.

Changeover Extinction (Signal But No Correlated Stimulus-EX 3). The effects of presenting the signal alone on changing over were examined by allowing response to initiate the signaled schedule for 1 -min periods, but without the correlated stimulus. Thus, by maintaining a sufficient rate of changeover, responding Ss could remain in signaled avoidance, but without the correlated stimulus to identify it. It should be noted that extinction always refers to changeover responding and never to avoidance responding.

\section{Results}

The data from each of the three animals are contained in Table 1. A relatively complete record for S A90 is found in Fig. 1. As shown, the response pattern across the various conditions for each $\mathrm{S}$ was similar for each of the measures. The most important measure was the amount of time spent in the signaled condition. Within three sessions after introducing the changeover condition (CO), Ss were spending from $85 \%-95 \%$ of the time in the signaled condition (Table 1).

After changeover responding stabilized under the changeover condition (CO), the EX 3 condition was put into effect. Under this condition, the changeover contingency consisted of presenting the signaled avoidance schedule but withholding the correlated stimulus which identified it. With this condition, changeover responding dropped to, or near, baseline levels (Table 1). When the regular changeover contingency was reinstated (i.e., both correlated stimulus and signaled schedule), changeover responding increased to a point where Ss were spending between $90 \%$ and $95 \%$ of the time in the signaled condition. Additional replications of these conditions gave identical results. In each instance, when the correlated stimulus was not part of the changeover contingency, changeover responding dropped to baseline levels. These results are identical to those reported by Badia et al (1971) for four of their Ss. In an effort to insure that Ss came into 
Table 1

Data from the Last Three Days of Each Condition*

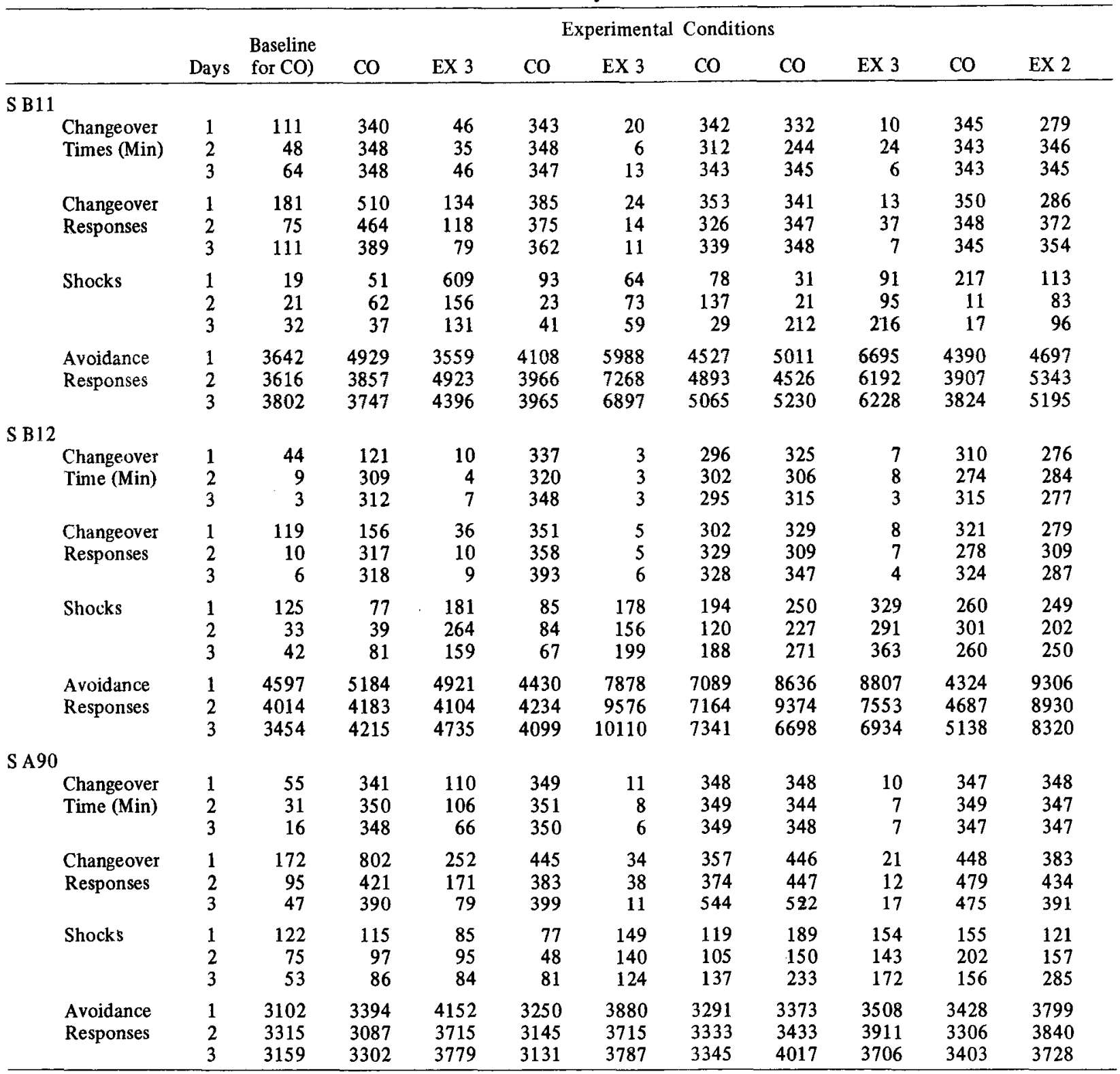

*Maximum changeover time was 360 min. Regular changeover (CO) refers to the contingency in which the correlated stimulus was presented immediately following a changeover response for a 60-sec period during which the signal preceded shock. The EX 3 contingency refers to the condition in which the signal preceded shock but the correlated stimulus was not presented. Under the $E X 2$ contingency, the correlated stimulus was presented but the signaled schedule withheld.

contact with the condition of signal alone (EX 3), the particulars of the present experiment differed from those of Badia et al. As noted, shorter R-S and S-S intervals were used, and several replications of the EX 3 condition were given in the present experiment. However, as seen in Table 1 , these changes had little effect on the time spent in the changeover condition. It is clear that some stimulus other than the signal maintains changeover performance.

The marked control of the correlated stimulus on changeover responding was also reflected by performance under the EX 2 condition. This finding suggests the source of control over changeover responding. Under this condition, the changeover contingency consisted of presenting the correlated stimulus but withholding the signal (i.e., unsignaled avoidance remained in effect). With this contingency in effect, each $\mathbf{S}$ continued changing over at a rate nearly equal to that under the regular changeover condition (Table 2). The control exerted by the correlated stimulus alone is not surprising. As noted earlier, shock almost invariably occurred in the presence of both correlated stimulus and signal, or in the absence of both of them. In contrast, the correlated stimulus in the absence of the signal identified a relatively shock-free (safe) period and, based upon this, it may have acquired 


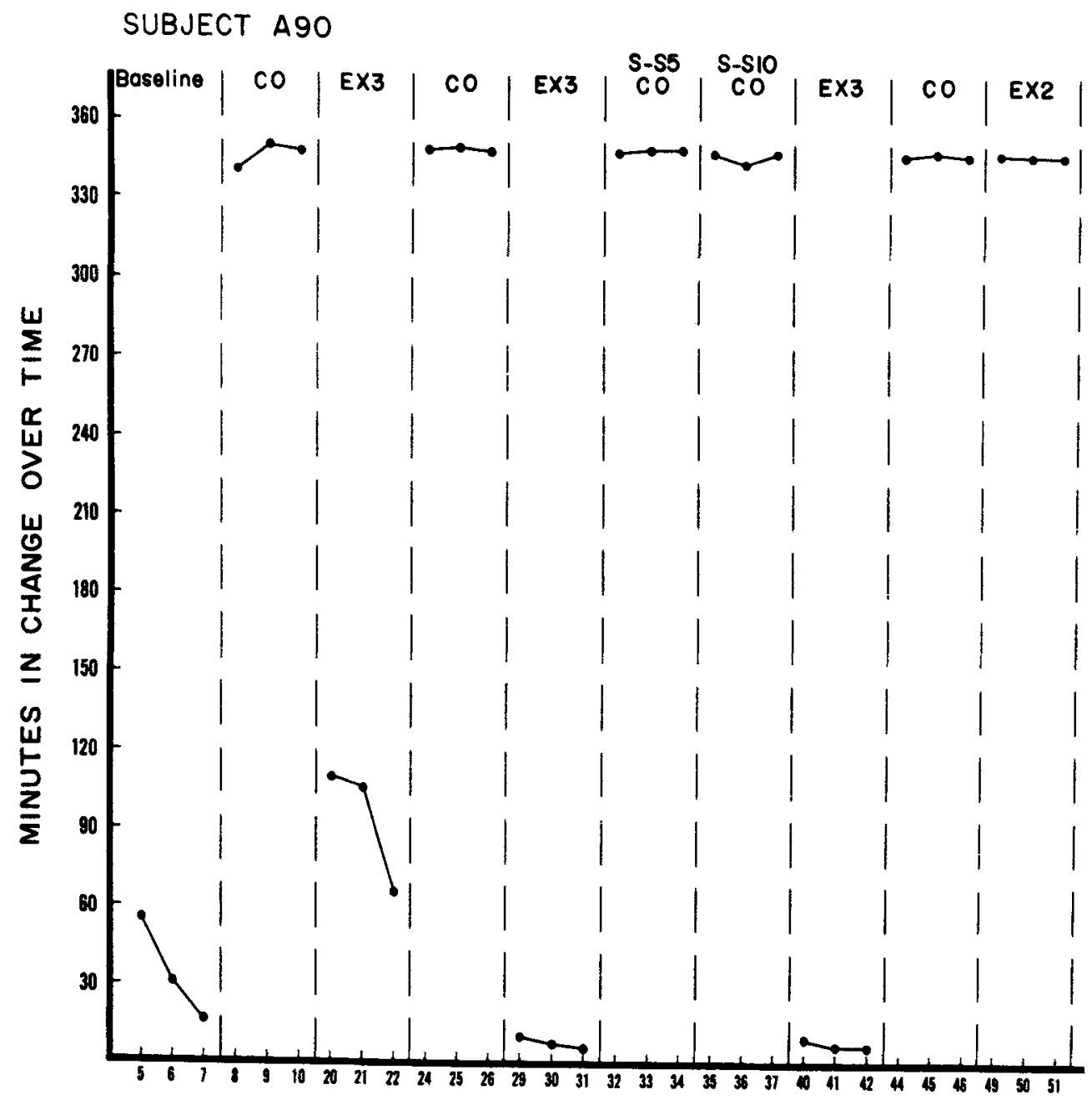

SIX HOUR SESSIONS

Fig. 1. Percent of session time spent in the changeover condition for the last three sessions of each condition. Conditions appear in the order that they were administered.

conditioned-reinforcing properties. This analysis suggests further that the compound of the correlated stimulus and signal should be aversive.

In general, both shocks and avoidance responses tended to be higher under the unsignaled condition, and it is tempting to attribute changeover responding to these factors. One could argue that when the signaled condition was changed, Ss received fewer painful shocks and expended less energy. The strongest argument against this interpretation is that Ss behave identically when shock is unavoidable but escapable and when shock is unavoidable and inescapable (Badia \& Culbertson, 1972). Under the latter conditions, shock and response rates are the same for both the signaled and unsignaled conditions.

\section{EXPERIMENT II}

Changeover responding dropped markedly under the signal-alone condition (EX 3 ) even though the signaled avoidance schedule continued to be presented following a changeover response. In contrast, when only the correlated stimulus was presented and the signal withheld, changing over occurred at a high rate. The importance of the correlated stimulus in controlling changeover responding is apparent, but the specific role it plays is puzzling. One important function that it may serve is that of providing the $S$ with immediate feedback (reinforcement) that a shock-free period is in effect. Thus, the continued presence of the correlated stimulus may be unnecessary. To test this notion, both feedback and no-feedback conditions were presented. Under the feedback condition, the correlated stimulus was presented for only a 1 -sec period following a changeover response. The no-feedback condition was the same as EX 3 of the first experiment in that the signaled avoidance schedule was presented, but the correlated stimulus was withheld following a changeover response. The remaining condition consisted of presenting the 1 -sec correlated stimulus, but withholding the signaled schedule. The Ss used in the first experiment were also used in the second one. 
Table 2

Data from the Last Three Days of Each Condition*

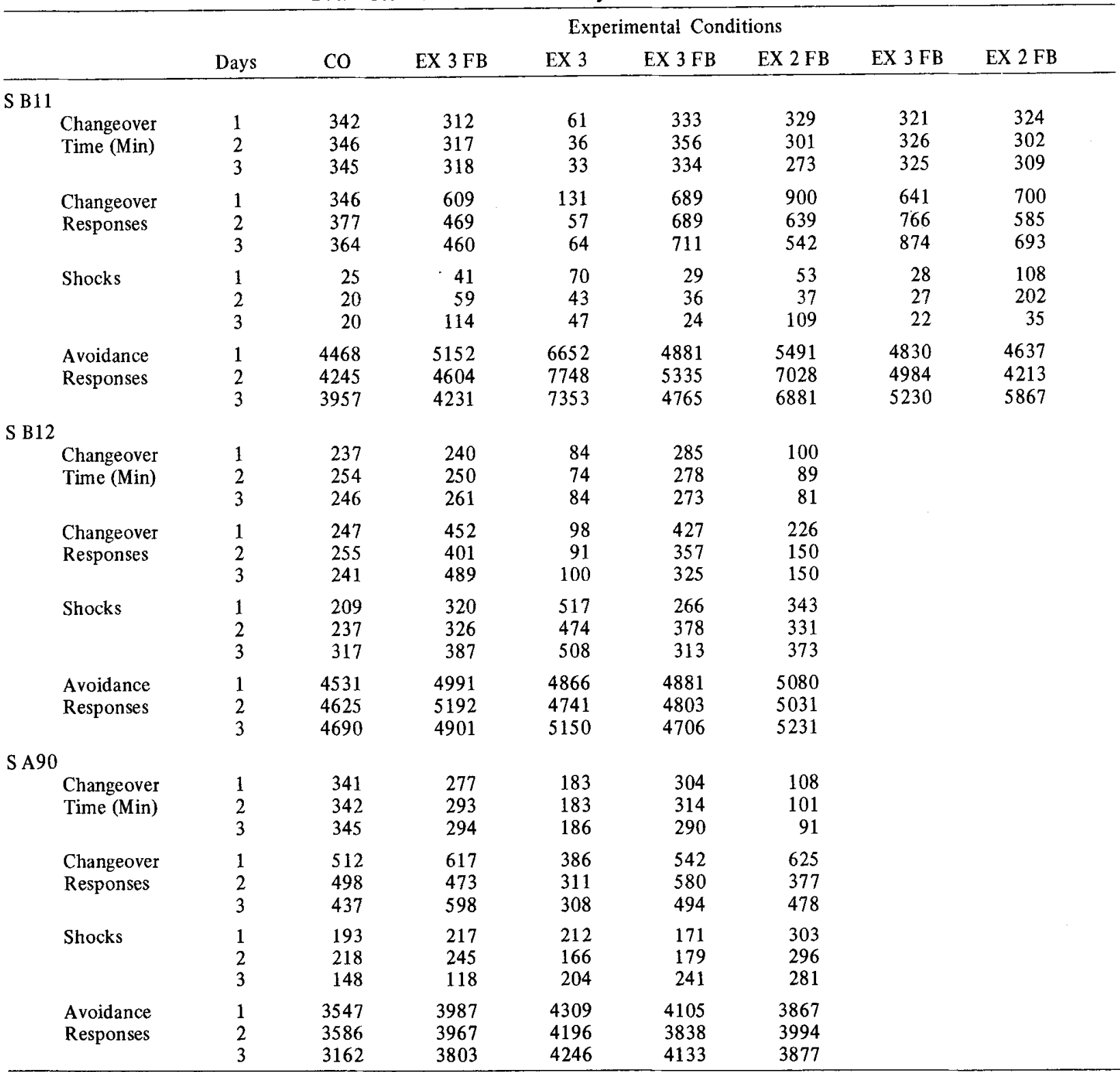

* Maximum changeover time was 360 min. Regular changeover (CO) refers to the contingency in which the correlated stimulus remained on for $60 \mathrm{sec}$ during which the signal preceded shock. The EX 3 contingency refers to the condition in which the signal preceded shock but the correlated stimulus withheld. Under the EX 3 FB contingency, the signal preceded shock and a 1-sec correlated stimulus followed the changeover response. Under the EX 2 FB contingency, a 1-sec correlated stimulus followed the changeover response but the signaled schedule was withheld.

The conditions were identical to those of the first experiment except for the duration of the correlated stimulus. A changeover response produced only a 1-sec presentation of the correlated stimulus, but produced the signaled schedule for a 1-min period. Additional responses within this 1 -min period were ineffective (i.e., did not alter the 1-min interval or result in further presentations of the $1-\sec$ correlated stimulus).

\section{Results}

The data for the three Ss of the second experiment are found in Table 2 and Fig. 2. It is evident that when the changeover contingency consisted of a $1-\mathrm{sec}$ correlated stimulus and the signaled avoidance schedule (EX $3 \mathrm{FB}$ ), responding for each $\mathrm{S}$ remained at a high level. However, when the $1-\mathrm{sec}$ correlated stimulus was removed from the contingency and only the signaled avoidance condition presented (EX 3), changeover responding dropped to near baseline levels for all Ss.

For two of the three Ss (B12 and A90), simply presenting the 1-sec correlated stimulus, without providing the signaled avoidance condition, was not sufficient to maintain responding. Under this condition, changeover responding dropped to baseline levels. This 
SUBJECT BII

SUBJECT B 12

SUBJECT A90

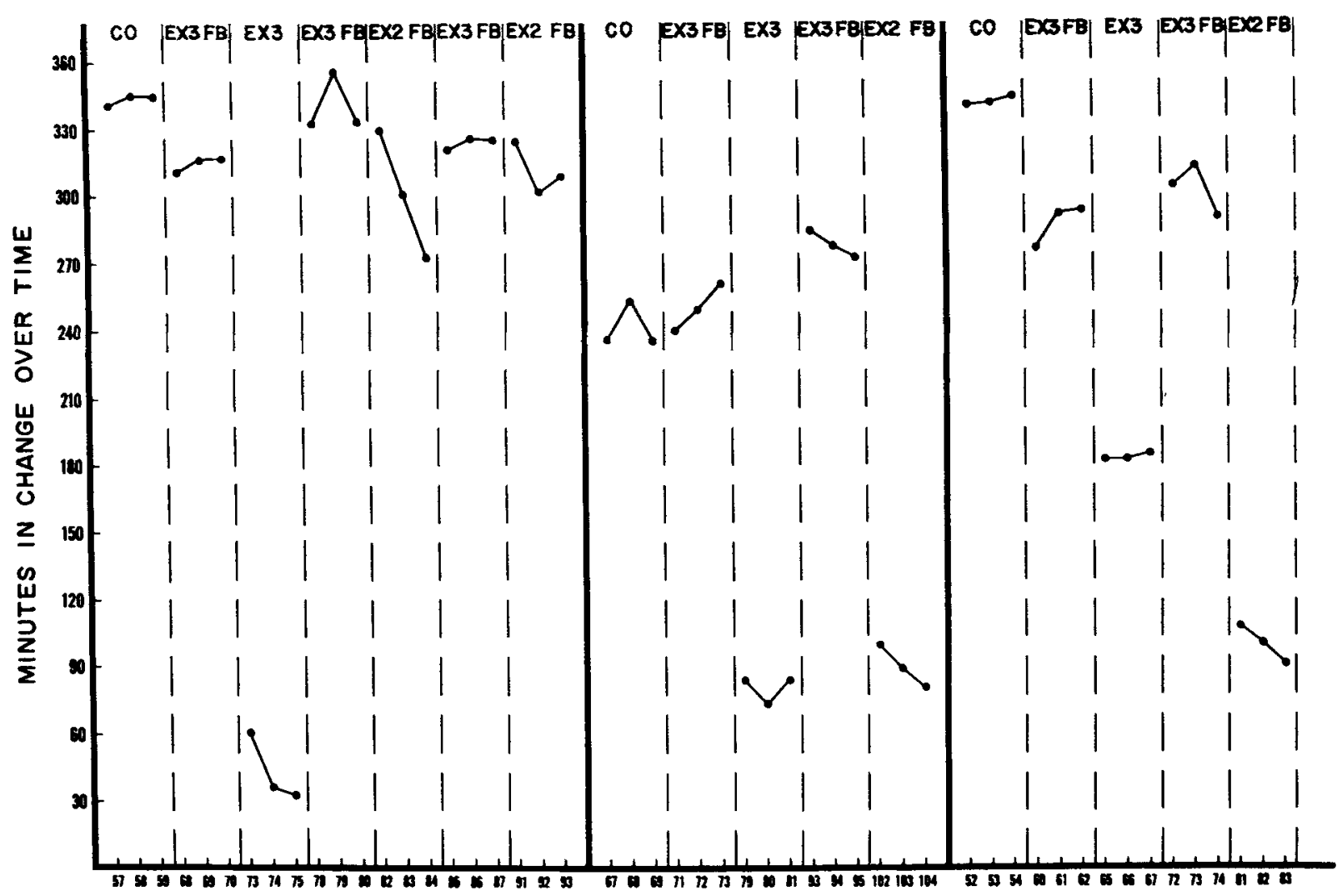

\section{SIX HOUR SESSIONS}

Fig. 2. Percent of session time spent in the changeover condition for the last three sessions of each condition. Conditions appear in the order that they were administered.

was not the case for S B11. The 1-sec exposure of the correlated stimulus alone (EX 2 FB), without the signaled schedule, was apparently sufficient to maintain changing over at a high level for this latter $\mathrm{S}$. Changeover responding for this $S$ continued at a high level for the last six 6-h sessions of the experiment, three of which are shown in Fig. 2.

Relative to the regular changeover condition, the number of changeover responses, avoidance responses, and shocks increased under the EX 3 FB condition. The increase in these response measures suggests that, while this condition will maintain changeover responding, the efficiency of performance is reduced. The most obvious reason for the latter is that the shock-free periods are no longer as identifiable with the $1-\mathrm{sec}$ stimulus relative to the regular changeover condition.

\section{GENERAL DISCUSSION}

It is apparent that when both the correlated stimulus and signal were presented, in contrast to either one being presented alone, control over changeover responding was greatest. Whether the correlated stimulus remained on throughout the changeover period or whether it was presented for a 1-sec period had little effect on the time spent in the changeover condition if the signaled schedule was also presented. In contrast, presenting the signaled schedule and withholding the correlated stimulus resulted in a marked decrease in changing over. However, presenting the correlated stimulus for the entire changeover period but withholding the signaled schedule had little effect (EX 1), since Ss continued changing over. In the second experiment, this latter finding occurred for only one of the three Ss. However, it took over several 6-h sessions for the two Ss which did not continue changing over before a decrement in changeover responding occurred. Based upon these data, it would appear that the correlated stimulus acquires properties similar to those of a conditioned positive reinforcer. In this regard, the data support the earlier interpretation of choice, which suggests that the preference for a signaled shock situation is maintained by stimuli identifying shock-free (safe) periods (Badia et al, 1971; Badia \& Culbertson, 1972). 


\section{REFERENCES}

Badia, P., \& Culbertson, S. The relative aversiveness of signalled vs unsignalled escapable and inescapable shock. Journal of the Experimental Analysis of Behavior, 1972, 17, 463-471.

Badia, P., Culbertson, S., \& Lewis, P. The relative aversiveness of signalled vs unsignalled avoidance. Joumal of the Experimental Analysis of Behavior, 1971, 16, 113-121.

\section{NOTE}

1. The notation identifying the conditions is the same as that used in previously published studies. We have retained the notation here to facilitate comparisons between them.

(R eceived for publication May 14, 1974; revision received June $17,1974$. ) 